Article

\title{
People's life and psychological change after quarantining Wuhan: Influence of the epidemic of Covid-19
}

\author{
Ling Zhang ${ }^{1,+}$, Qi Chen ${ }^{1,+}$, Yan Yu ${ }^{1}$, Hui Yao ${ }^{1}$, Sirong Zhu ${ }^{1}$ and Xiaodong Tan ${ }^{1, *}$ \\ 1 School of Health Sciences, Wuhan University, Wuhan 430071, China \\ * Correspondence: 00300469@whu.edu.cn; Tel.: +86-1350-713-5465 \\ † These authors contributed equally to this manuscript and were listed as co-first authors.
}

\begin{abstract}
The epidemic of Coronavirus Disease 2019 (Covid-19) has brought many changes to people's life. This study aims to analysis Chinese people's psychological change and life after quarantining Wuhan and explore the influencing factors. Based on data from a web-survey after quarantining Wuhan $(\mathrm{N}=3268)$, the principal-component-analysis (PCA), multiple-linear-regression (MLR), propensity-score-matching (PSM) were used to explore the psychological change of people in China and the influencing factors. $83.3 \%$ of the respondents said that the impact of the epidemic on their life had increased after quarantining Wuhan. A considerable proportion of people's anxiety increased, being reflected in negative emotion, behavioral response and physiological response. The proportion of people who said their anxiety had increased in Wuhan was higher than that in other regions $(p<0.05)$. The anxiety of people who were in medical isolation increased less than those who were not $(p<0.05)$. All three aspects of people's anxiety were positively related with time of medical isolation and degree of the attention on the epidemic $(p<0.05)$ except the effect of attention degree on the physiological response $(p=0.06)$. The measure of medical isolation at home should be advocated. Yet people should reduce the concern for the epidemic while paying attention to selfprotection.
\end{abstract}

Keywords: anxiety; psychological health; public health; COVID-19

\section{Introduction}

Coronavirus Disease 2019 (Covid-19) attracted people's attention when it was identified in Wuhan, Hubei Province, China, in December 2019. As early as January 23, considering that the migration of people will accelerate the spread of disease, Wuhan imposed traffic restrictions and restricted all access to and from Wuhan [1]. Subsequently, first level response was initiated in all provinces, regions and cities in Chinese mainland. National authorities continuously published and updated epidemic information, and issue corresponding policy documents and measures for prevention and control.

The main features of public health emergencies are its sudden, unknown and rapid occurrence and progress, directly related to public health, economic development and social stability [2]. Facts are unclear in the early stages of a major incident. How many people are infected with Covid-19 indeed? What is the fatality rate of Covid-19? What should and could ordinary people do? How to guarantee people's normal life under the background of shutdown? And so forth. Despite fear of death, the COVID-19 pandemic may raise people's feelings of isolation, helplessness and insecurity [3]. The emergence of Covid-19 is creating a tricky and rapidly evolving situation, accompanied by some chain social effects, such as a surge of demand for face masks and concerns about food shortages. The high infectivity, the uncertainty and unaware of the novel virus have caused a lot of social worries and some people's radically panic response. 
In order to put Covid-19 under control and protect health and life security of people, relevant local authorities have taken necessary quarantine measures towards the high-risk populations to cut off the source of infection. Since then, more and more people have gradually realized the seriousness of the situation and different degrees of such as tension, anxiety, worry, depression, panic and other psychological crises grow [4]. Frontline medics and scientists in China are playing a leading role in battling the outbreak of Covid-19, facing the epidemic directly, suffering constantly increasing workload and psychological pressure [5,6]. Without party and travel, people have more time to sit around at home paying more attention to the progress of the epidemic, and some people are getting more and more anxious and fidgety. Meanwhile, some local departments and grass-roots organizations have not done their work in place, which has increased the difficulty of control and prevention of the epidemic, raising public concern, dissatisfaction and even anger. Some speculation and rumors are pouring in at the same time [7]. Inaccurate or false speculation and rumors can arouse negative and detrimental social reactions, such as irritability and aggressive behavior [8].

Anxiety is defined as troubled feeling in the mind caused by fear and uncertainty about the future [9]. Studies have shown that anxiety could cause individual physiological, emotional, intellectual, social and spiritual responses [10]. Especially in the event of major public health emergencies, it was difficult for people to grasp and recognize the new situation to meet their own needs, resulting in a sharp decline in sense of security, which provided the necessary conditions for the emergence of social anxiety. To a certain extent, individual anxiety would form social tension, which was released in social conflict or other ways eventually. For example, the exclusion of people from the epidemic area, the spread of rumors on social media and other stigmatization of the epidemic have adversely affected the prevention and control of the epidemic [11]. The impact of pandemic of infectious disease is not only limited to the people who are infected, the number of people whose mental health is affected by the epidemic can not be underestimated, often far more than the number of people affected by the infection [12]. A study found that $52.1 \%$ of participants felt horrified and apprehensive due to the epidemic of Covid-19 [13]. Fear in a pandemic may develop various psychiatric disorders [14]. Even healthy individuals will suffer from anxiety and stress let alone those with pre-existing psychiatric disorders [15].

The quarantine will inevitably have some impacts on residents' daily life and psychology, thus affecting the stability of the society. While paying attention to Covid-19, we should also attach importance to people's mental health. Some studies have pointed out the importance of timely mental health care [16, 17], yet mostly focus on psychological state of the medical workers. However, what are the mental states of ordinary people who occupy a larger number? Will the citizens of Wuhan be more frightened because they are in a serious epidemic area? Will the large number of people who are isolated for being clinically-confirmed, suspected cases, fever or close contacts be more anxious due to medical isolation? These are issues deserving deeply exploration and consideration.

The main purpose of our study was to fully understand and track the changes of people's mental states and life in different situations and explore the influencing factors at the end of the first incubation period after Wuhan was quarantined. These will help to provide evidence for relevant departments to formulate special psychological interventions and give some suggestions for the rest of the world to better fight Covid-19.

\section{Materials and Methods}

\subsection{Study design and sampling}

Using a self-designed questionnaire, we conducted a survey to investigate the residents' psychological state and life style from February 1 to February 4, the second week after Wuhan sealed off the city. The measure of anxiety was designed by Delphi method and documents. Based on previous research and compiled after the discussion of experts, the questionnaire was mainly divided into three parts: personal basic information, mental state scale and life state.

We surveyed in the form of online questionnaire for it was impossible to conduct large-scale field investigation during the epidemic. The method of complete random sampling was used. It can 
quickly reflect the difference between the serious epidemic area and the non-serious epidemic area during the epidemic period, and eliminate the deviation between the samples through the comparison of the two, so as to truly reflect the mentality and achieve the purpose of this study. 3268 valid questionnaires were collected, covering all provinces and autonomous regions except Tibet, there are also a few from abroad.

\subsection{Measures}

The measure of anxiety refers to the Beck Depression and Anxiety Inventories (BDI) [18]. All items of anxiety was expressed on a 5-point Likert scale. Numbers 1-5 represent decrease a lot, decrease slightly, no change, increase slightly, increase a lot, respectively. The KMO value of our anxiety scale was $0.914(p<0.001)$, which suggested a good validity. We divided anxiety into three categories, including Emotion, Behavioral Response and Physiological Response through PCA. The reliability analysis shows that the Cronbach's $\alpha$ coefficient of the general scale was 0.866 , which suggested a good reliability of the scale designed. The Cronbach's $\alpha$ of Behavioral Response was 0.625, and the other two dimensions were higher than 0.8. More details are shown in Table 1. We ended up using PCA to generate factor weighted scores of Emotion, Behavioral Response and Physiological Response to evaluate people's anxiety.

Table 1. Measures of Anxiety

\begin{tabular}{ccccc}
\hline Anxiety & Scale & Mean & SD & Reliability $(\boldsymbol{\alpha})$ \\
\hline$\quad$ Negative Emotion & & & & 0.877 \\
f1 I feel nervous, anxious or impatient & $1-5$ & 3.57 & 1.08 & \\
f2 I feel sad and want to cry & $1-5$ & 3.12 & 1.01 & \\
f3 I'm afraid of the development of the & $1-5$ & 3.58 & 1.09 & \\
$\quad$ epidemic & & & & \\
$\quad$ f4 I feel tired & $1-5$ & 3.02 & 0.92 & \\
f5 I feel irritable and angry & $1-5$ & 3.00 & 0.89 & \\
$\quad$ f6 I feel lonely & $1-5$ & 3.04 & 0.91 & \\
$\quad$ Behavior Response & & & & \\
f7 My interest in things & $1-5$ & 3.02 & 0.91 & \\
$\quad$ f8 My sleep time & $1-5$ & 3.38 & 1.03 & \\
$\quad$ f9 My appetite & $1-5$ & 3.00 & 0.75 & \\
f10 My weight & $1-5$ & 3.34 & 0.75 & \\
$\quad$ Physiological Response & & & & \\
\hline f11 I have the idea of killing or hurting myself & $1-5$ & 2.67 & 0.78 & \\
f12 I have difficulty in making a decision & $1-5$ & 2.97 & 0.72 & \\
$\quad$ f13 I feel palpitations & $1-5$ & 2.94 & 0.77 & \\
f14 I feel chest tightness and breathing & $1-5$ & 2.88 & 0.73 & \\
$\quad$ difficulties & & & & \\
f15 I feel uneasy and unable to sit still & $1-5$ & 2.97 & 0.78 & \\
f16 I feel muscle soreness and restricted & $1-5$ & 3.07 & 0.84 & \\
\hline
\end{tabular}

\subsection{Statistical Analysis}

The principal component analysis (PCA), independent sample t-test, one-way analysis of variance (ANOVA), multiple linear regression (MLR) and propensity score matching (PSM) were used in the present study. PCA was used to check the validity and calculate the score of the three dimensions of anxiety used in this study. Specifically, Kaiser-Meyer-Olkin (KMO) and Bartlett were used to test the validity of the scale. Reliability analysis was used to calculate the reliability of the scale. In addition, PCA was used to generate factor weighted scores of corresponding dimensions to 
assess people' anxiety. ANOVA and MLR were used to explore the influence of different factors on anxiety. Subsequently, PSM was used for robustness test. Based on the theoretical framework of counterfactual inference model, PSM can reduce the influence of data bias and confounding variables, so as to make a more reasonable comparison between the experimental group and the control group. PSM has been proved to be a useful, novel and creative statistical method when using non experimental data or observation data to evaluate the intervention effect [19]. The propensity score matching models were as follows:

$$
\begin{gathered}
e\left(X_{i}\right)=E\left(T_{i}=1 \mid X_{i}\right) \\
A T T=E(Y 1-Y 0 \mid T=1) \\
A T U=E(Y 1-Y 0 \mid T=0) \\
A T E=E(Y 1-Y 0 \mid T)
\end{gathered}
$$

$X_{i}$ represented all the observed covariates. Regions and medical isolation were regarded as a Treatment separately. Propensity score, $e\left(X_{i}\right)$, was defined as the conditional probability that individual $i$ received the treatment when controlling for all the observed covariates $X_{i}$ before receiving the treatment. $Y 1$ represented the outcome of those who have been exposed to the treatment, $Y 0$ for those who have not. ATE represented the expected variation of the same sample under different conditions of regional or medical isolation, while ATT represented treated group and ATU represented untreated group.

In this paper, SPSS 20.0 and Stata 14.0 were used to conduct corresponding statistical analysis, and $p<0.05$ was considered to be statistically significant.

\section{Results}

This section may be divided by subheadings. It should provide a concise and precise description of the experimental results, their interpretation as well as the experimental conclusions that can be drawn.

\subsection{Socio-demographic characteristics}

A total of 3268 valid questionnaires were collected. The results of descriptive analysis show that $69.1 \%$ of the respondents in this study were female, and most respondents were young and middle-

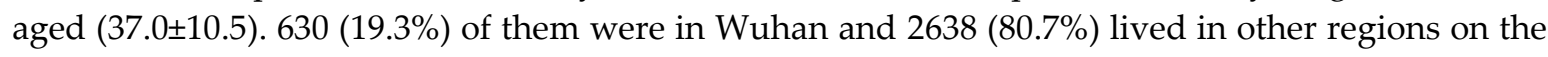
day of investigation. The education level of the respondents was concentrated in College/ University (64.8\%). $45.8 \%$ of them were in medical isolation. Details are shown in Table 2. 
Table 2. Demographic Characteristics of Samples

\begin{tabular}{|c|c|c|c|c|c|}
\hline Characteristics & Category/ Range & $\mathbf{n}$ & Mean & SD & $\%$ \\
\hline Age & $18-87$ & 3268 & 37.0 & 10.5 & \\
\hline Attention degree & $1-5$ & 3268 & 4.5 & 0.9 & \\
\hline \multirow[t]{2}{*}{ Sex } & "Male" =1 & 1010 & & & $30.9 \%$ \\
\hline & "Female" $=2$ & 2258 & & & $69.1 \%$ \\
\hline \multirow{5}{*}{ Education } & "Primary school" =1 & 7 & & & $0.2 \%$ \\
\hline & "Junior high school" $=2$ & 158 & & & $4.8 \%$ \\
\hline & "Senior high school" = 3 & 483 & & & $14.8 \%$ \\
\hline & "College/ University" $=4$ & 2118 & & & $64.8 \%$ \\
\hline & "Postgraduate" $=5$ & 502 & & & $15.4 \%$ \\
\hline \multirow[t]{2}{*}{ Marital status } & "Unmarried" $=0$ & 1063 & & & $32.5 \%$ \\
\hline & "Married" = 1 & 2205 & & & $67.5 \%$ \\
\hline \multirow[t]{2}{*}{ Job status } & "Have a job" =1 & 2606 & & & $79.7 \%$ \\
\hline & "Have no job" = 2 & 662 & & & $20.3 \%$ \\
\hline \multirow[t]{5}{*}{ Income } & $"<2000 "=1$ & 469 & & & $14.4 \%$ \\
\hline & “2000-5000” =2 & 1081 & & & $33.1 \%$ \\
\hline & $" 5001-10000 "=3$ & 968 & & & $29.6 \%$ \\
\hline & $“ 10001-15000 ”=4$ & 388 & & & $11.9 \%$ \\
\hline & $">15000 "=5$ & 362 & & & $11.1 \%$ \\
\hline \multirow[t]{2}{*}{ City (location) } & "Wuhan" = 1 & 630 & & & $19.3 \%$ \\
\hline & "Other regions" $=2$ & 2638 & & & $80.7 \%$ \\
\hline \multirow[t]{2}{*}{ Medical isolation status } & "Yes" = 1 & 1498 & & & $45.8 \%$ \\
\hline & $" \mathrm{No}^{\prime}=0$ & 1770 & & & $54.2 \%$ \\
\hline \multirow[t]{2}{*}{ Are there any patients around } & $" \mathrm{No}^{\prime}=0$ & 2794 & & & $85.5 \%$ \\
\hline & “Yes" = 1 & 474 & & & $14.5 \%$ \\
\hline
\end{tabular}

\subsection{People's psychological change}

There were different changes in the mental states of responders after Wuhan was quarantined. Among them, the respondents who had more negative emotions are the most. According to the survey, $60.1 \%$ of the responders felt more nervous, anxious or impatient, and $60.4 \%$ of the responders were more afraid of the development of the epidemic, accounting for a considerable proportion. Besides, people's sadness (28.9\%), weariness (21.7\%), irritability (19.6\%) and loneliness $(21.3 \%)$ also increased in varying degrees. Some of the respondents had various physiological responses, for example, $22.2 \%$ of the respondents had muscular pains and aches and $22.2 \%$ of the respondents felt unable to sit still. As for behavior response, $42.7 \%$ of the respondents had an increase in sleep time and $34.8 \%$ of the respondents gained weight. $16.5 \%$ of the respondents said that their appetite declined, while $15.9 \%$ of the respondents said that their appetite increased. Details are shown in Table 3. 
Table 3. Psychological change of samples

\begin{tabular}{ccccccc}
\hline Dimensions & Indicators & $\begin{array}{c}\text { decrease } \\
\text { a lot }\end{array}$ & $\begin{array}{c}\text { decrease } \\
\text { slightly }\end{array}$ & $\begin{array}{c}\text { no } \\
\text { change }\end{array}$ & $\begin{array}{c}\text { increase } \\
\text { slightly }\end{array}$ & $\begin{array}{c}\text { increase } \\
\text { a lot }\end{array}$ \\
\hline Negative emotion ${ }^{1}$ & & & & & & \\
& $\mathrm{f} 1$ & $7.4 \%$ & $6.3 \%$ & $26.2 \%$ & $42.0 \%$ & $18.1 \%$ \\
& $\mathrm{f} 2$ & $10.3 \%$ & $5.1 \%$ & $55.7 \%$ & $19.8 \%$ & $9.1 \%$ \\
& $\mathrm{f} 3$ & $7.3 \%$ & $6.7 \%$ & $25.6 \%$ & $42.0 \%$ & $18.4 \%$ \\
& $\mathrm{f} 4$ & $10.3 \%$ & $4.4 \%$ & $63.6 \%$ & $15.9 \%$ & $5.8 \%$ \\
& $\mathrm{f} 5$ & $10.0 \%$ & $4.7 \%$ & $65.7 \%$ & $14.6 \%$ & $5.0 \%$ \\
& $\mathrm{f} 6$ & $9.8 \%$ & $4.1 \%$ & $64.8 \%$ & $15.1 \%$ & $6.2 \%$ \\
\hline Behavioral response $^{2}$ & & & & & & \\
& $\mathrm{f} 7$ & $7.4 \%$ & $11.8 \%$ & $58.6 \%$ & $15.9 \%$ & $6.3 \%$ \\
& $\mathrm{f} 8$ & $5.1 \%$ & $9.8 \%$ & $42.3 \%$ & $27.1 \%$ & $15.7 \%$ \\
& $\mathrm{f} 9$ & $3.8 \%$ & $12.7 \%$ & $67.6 \%$ & $11.8 \%$ & $4.1 \%$ \\
& $\mathrm{f} 10$ & $1.6 \%$ & $5.1 \%$ & $58.7 \%$ & $27.4 \%$ & $7.3 \%$ \\
\hline Physiological response $^{3}$ & & & & & & \\
& $\mathrm{f} 11$ & $16.7 \%$ & $2.0 \%$ & $79.8 \%$ & $1.0 \%$ & $0.5 \%$ \\
& $\mathrm{f} 12$ & $7.0 \%$ & $3.5 \%$ & $76.9 \%$ & $10.2 \%$ & $2.4 \%$ \\
& $\mathrm{f} 13$ & $9 . \%$ & $2.1 \%$ & $76.3 \%$ & $9.7 \%$ & $2.5 \%$ \\
& $\mathrm{f} 14$ & $10.1 \%$ & $1.7 \%$ & $79.6 \%$ & $7.1 \%$ & $1.5 \%$ \\
& $\mathrm{f} 15$ & $9.2 \%$ & $2.0 \%$ & $74.0 \%$ & $12.3 \%$ & $2.5 \%$ \\
& $\mathrm{f} 16$ & $8.6 \%$ & $1.8 \%$ & $67.4 \%$ & $17.9 \%$ & $4.3 \%$ \\
\hline
\end{tabular}

Notes:

${ }^{1}$ Negative Emotion: f1 I feel nervous, anxious or impatient, f2 I feel sad and want to cry, f3 I'm afraid of the development of the epidemic, f4 I feel tired, f5 I feel irritable and angry, f6 I feel lonely.

${ }^{2}$ Behavior Response: 7 7 My interest in things, f8 My sleep time, f9 My appetite, f10 My weight.

${ }^{3}$ Physiological Response: f11 I have the idea of killing or hurting myself, f12 I have difficulty in making a decision, f13 I feel palpitations, f14 I feel chest tightness and breathing difficulties, f15 I feel uneasy and unable to sit still, f16 I feel muscle soreness and restricted.

\subsection{Comparison on the mental states of people in Wuhan and other regions}

Figure 1 shows that there were different changes in mental states between respondents in Wuhan and other regions, all differences were statistically significant $(p<0.05)$ despite in f8 $(p=$ $0.059), \mathrm{f} 11(p=0.575)$ and $\mathrm{f} 12(p=0.076)$. It is not difficult for us to find out from the figure that the increased proportion of people in all indicators of Negative Emotions and Physiological Response in Wuhan was higher than that in other regions. As for Negative Emotions, the top two biggest proportion differences value were people's perception of sadness $(10.0 \%)$ and weariness $(8.4 \%)$. Besides, $66.3 \%$ of the responders in Wuhan felt more nervous, anxious or impatient, and $66.2 \%$ were more afraid of the development of the epidemic, among which $23.3 \%$ and $22.4 \%$ felt that there was a lot of increase, while the corresponding proportions were $58.6 \%$ and $59.0 \%$ in other regions. As for Physiological Response, 28.1\% of the responders in Wuhan felt more muscle soreness and restricted, $21.7 \%$ felt more uneased and unable to sit still and $18.4 \%$ felt more palpitation, while the proportion of other regions was $20.9 \%, 13.1 \%$ and $10.6 \%$, respectively. 


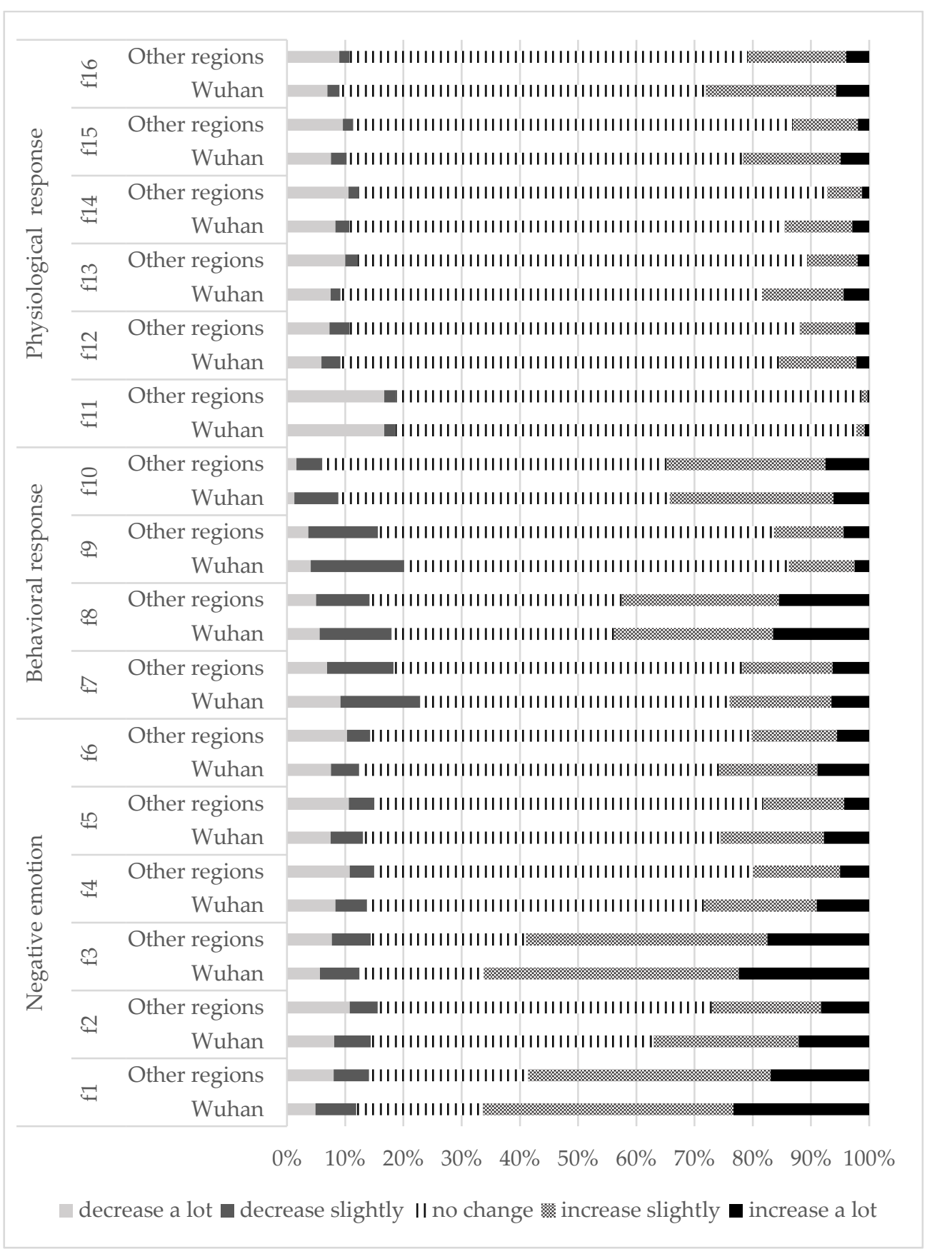

Figure 1. Change of psychological state of samples in different regions

We further used PCA to generate factor weighted scores of Negative Emotion, Behavioral Response and Physiological Response and conducted independent sample t-test to analyse the difference of people's mental status in two regions. The results verified that the anxiety of people in Wuhan was more common than that in other regions in China $(p<0.05)$. Details are shown in Table 4. 
Table 4. Results of t-test

\begin{tabular}{cccccccc}
\hline & Region & $\mathbf{n}$ & Mean & SD & D (a-b) & 95\% CI & $p$ \\
\hline Negative & Wuhan & 630 & 0.155 & 1.000 & 0.192 & $0.105 \sim 0.278$ & 0.000 \\
Emotion & Other regions & 2638 & -0.037 & 0.997 & & & \\
& & & & & & & \\
Behavioral & Wuhan & 630 & -0.082 & 0.998 & -0.102 & $-0.189 \sim-0.015$ & 0.022 \\
Response & Other regions & 2638 & 0.020 & 1.000 & & & \\
Physiological & Wuhan & 630 & 0.098 & 1.005 & 0.122 & $0.035 \sim 0.209$ & 0.006 \\
Response & Other regions & 2638 & -0.023 & 0.998 & & & \\
\hline
\end{tabular}

Notes: *a is the mean score of the responders in Wuhan, b is the mean score of the responders in other regions

\subsection{Comparison on the mental states of people in Wuhan and other regions}

Independent sample t-test, ANOVA and MLR were used to explore the influence of different factors on anxiety. Influence factors obtained statistically significant in t-test and ANOVA were included in MLR. Models 1 and 2 showed that people's negative emotion was significantly related with their regions, age, education, income, medical isolation status, days of medical isolation and attention degree, while their physiological response was significantly related with their regions, medical isolation status and attention degree. People who were in Wuhan $(p<0.05)$, or paid more attention to the epidemic $(p<0.05)$ gained more negative emotion and had stronger physiological response while people who were in medical isolation $(p<0.05)$ gained less negative emotion and physiological response. The increase of negative emotion was positively related to the level of people's education $(p<0.05)$ while negatively correlated with their income $(p<0.05)$. All three aspects of people's anxiety were positively related with longer time of medical isolation and higher degree of the attention on the epidemic $(p<0.05)$ except the effect of attention degree on the physiological response was not statistically significant $(p=0.06)$. Whether people had a job or were in marriage were not related with the change of anxiety $(p>0.05)$. More concrete results of MLR are shown in Table 5 . 
Table 5. Results of MLR

\begin{tabular}{|c|c|c|c|c|c|c|c|c|c|}
\hline & \multicolumn{3}{|c|}{$\begin{array}{l}\text { Negative emotion } \\
\text { (Model 1) }\end{array}$} & \multicolumn{3}{|c|}{$\begin{array}{c}\text { Behavior response } \\
\text { (Model 2) }\end{array}$} & \multicolumn{3}{|c|}{$\begin{array}{c}\text { Physiological response } \\
\text { (Model 3) }\end{array}$} \\
\hline & \multirow{2}{*}{ B } & \multicolumn{2}{|c|}{$95 \%$ CI } & \multirow{2}{*}{ B } & \multicolumn{2}{|c|}{$95 \%$ CI } & \multirow{2}{*}{ B } & \multicolumn{2}{|c|}{$95 \%$ CI } \\
\hline & & lower & upper & & lower & upper & & lower & upper \\
\hline Intercept & $-0.817^{*}$ & -1.245 & -0.389 & $-0.537^{*}$ & -0.975 & -0.099 & $0.393^{*}$ & -0.045 & 0.831 \\
\hline Regions & $-0.175^{*}$ & -0.262 & -0.087 & $0.122^{*}$ & 0.032 & 0.211 & $-0.139^{*}$ & -0.228 & -0.049 \\
\hline Age & $-0.005^{*}$ & -0.009 & -0.001 & -0.004 & -0.008 & 0.000 & -0.003 & -0.008 & 0.001 \\
\hline Sex & 0.046 & -0.027 & 0.119 & 0.020 & -0.054 & 0.094 & $-0.115^{*}$ & -0.189 & -0.040 \\
\hline Education & $0.085^{*}$ & 0.034 & 0.137 & -0.025 & -0.078 & 0.028 & 0.028 & -0.025 & 0.081 \\
\hline Job status & -0.060 & -0.158 & 0.038 & 0.020 & -0.080 & 0.120 & 0.001 & -0.099 & 0.101 \\
\hline Income & -0.033 & -0.067 & -0.002 & $0.043^{*}$ & 0.008 & 0.078 & -0.022 & -0.057 & 0.013 \\
\hline Marital status & -0.000 & -0.090 & 0.089 & -0.021 & -0.113 & 0.070 & -0.058 & -0.150 & 0.033 \\
\hline $\begin{array}{l}\text { Medical } \\
\text { isolation }\end{array}$ & $-0.104^{*}$ & -0.195 & -0.013 & -0.021 & -0.114 & 0.073 & $-0.121^{*}$ & -0.215 & -0.028 \\
\hline $\begin{array}{l}\text { Days of } \\
\text { medical } \\
\text { isolation }\end{array}$ & $0.048^{*}$ & 0.010 & 0.086 & $0.062^{*}$ & 0.023 & 0.101 & $0.026^{*}$ & 0.013 & 0.065 \\
\hline $\begin{array}{l}\text { Attention } \\
\text { degree }\end{array}$ & $0.227^{*}$ & 0.189 & 0.265 & $0.065^{*}$ & 0.026 & 0.104 & 0.039 & 0.001 & 0.078 \\
\hline
\end{tabular}

Notes: $* \mathrm{p}<0.05$.

\subsection{Robustness test}

$55.4 \%$ of the respondents in Wuhan were in medical isolation, while the proportion was $43.7 \%$ in other regions. The above results showed that the anxiety of people who were out of the serious epidemic area $(p<0.05)$ and in medical isolation $(p<0.05)$ increased relatively less. In order to eliminate the influence of confounding factors, we conducted robustness test and Table 6 shows the results of PSM. The results show that people who were in Wuhan gained more negative emotion ( $p$ $<0.05)$ and had stronger physiological response $(\mathrm{p}<0.05)$ and who were in medical isolation had less negative emotion $(\mathrm{p}<0.05)$ and physiological response $(\mathrm{p}<0.05)$ above were confirmed in Models 4 and 6. However, people who were in other regions gained more behavior response $(\mathrm{p}<0.05)$ in Model 5.

Table 6. Results of PSM (robustness test)

\begin{tabular}{ccccccc}
\hline & $\begin{array}{c}\text { Negative emotion } \\
\text { (Model 4) }\end{array}$ & \multicolumn{2}{c}{$\begin{array}{c}\text { Behavior response } \\
\text { (Model 5) }\end{array}$} & \multicolumn{2}{c}{$\begin{array}{c}\text { Physiological response } \\
\text { (Model 6) }\end{array}$} \\
\cline { 2 - 7 } & Coef. & $\mathbf{P}>|\mathbf{z}|$ & Coef. & $\mathbf{P}>|\mathbf{z}|$ & Coef. & $\mathbf{P}>|\mathbf{z}|$ \\
\hline Wuhan (ref.) & 0.114 & 0.012 & -0.114 & 0.012 & 0.112 & 0.017 \\
Other regions & $\mathbf{- 0 . 1 5 1}$ & 0.002 & $\mathbf{0 . 1 3 5}$ & 0.006 & $\mathbf{- 0 . 1 3 9}$ & 0.006 \\
& & & & & & \\
Not in medical isolation & 0.135 & 0.008 & & & & 0.085 \\
(ref.) & & & -0.032 & 0.455 & 0.040 \\
In medical isolation & $\mathbf{- 0 . 1 7 7}$ & 0.004 & 0.008 & 0.894 & $\mathbf{- 0 . 1 8 2}$ & 0.001 \\
\hline
\end{tabular}

\subsection{Psychological adjustment}

According to our survey, $83.3 \%$ of the respondents said that the impact of the epidemic on their life had increased after the 23 January. $37.5 \%$ of the respondents in Wuhan held the opinion that their 
risk of infection had increased after Wuhan was quarantined, while $41.7 \%$ thought it decreased. The corresponding proportions in other regions were $41.5 \%$ and $35.4 \%$, respectively. $40.3 \%$ of the respondents in medical isolation believed that their risk of infection had increased after quarantining Wuhan, while $39.5 \%$ thought it decreased. The corresponding proportions in other regions were $41.0 \%$ and $34.1 \%$, respectively. $55.5 \%$ of the respondents believed that there was no need to adjust their mental states. Only $18.89 \%$ of the respondents who realized they had anxiety would turn to others for help. Actually, they were more inclined to take various ways to reduce psychological pressure on themselves, and their own ways of reducing anxiety were diverse. Figures 2 shows the way people chose to release themselves. From the figure we could find that the top three choices were watching TV $(71.0 \%)$, using instant messaging software $(69.3 \%)$ and chatting with family $(57.9 \%)$. Besides, $41.4 \%$ of the respondents chose eating while $27.4 \%$ chose exercise.

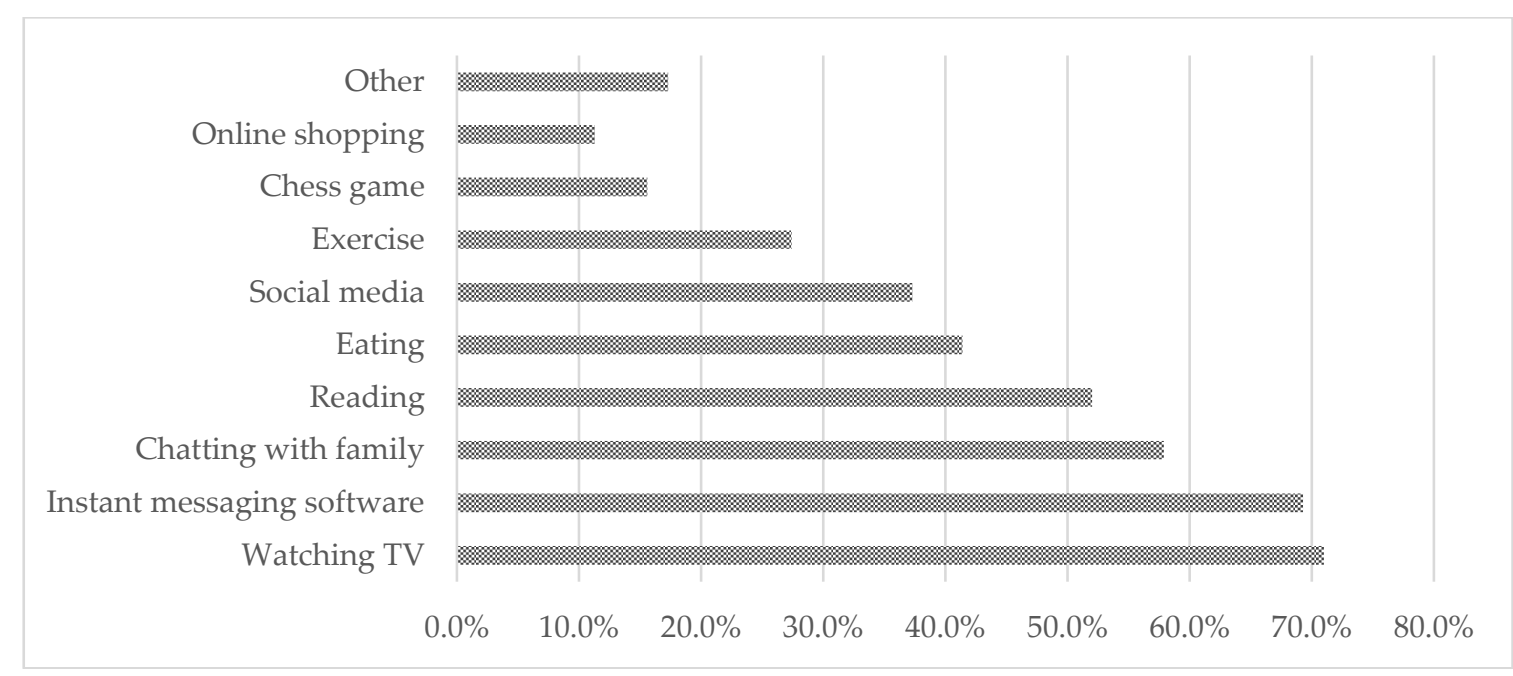

Figure 2. Methods to releave themselves chosen by samples

\section{Discussion}

Anxiety is a state produced by human body in the face of various external stimuli. Public health emergencies, especially major infectious disease outbreaks are easy to cause negative psychological response, and serious events can also form post-traumatic stress disorder (PTSD). Previous studies prove that psychological factors can affect the social stability and development by affecting individual behavior [20,21]. The stock market of many countries has fallen sharply for several days, suffered heavy losses, and there has been a crisis in economic development and social order. In a panic over the outbreak, people in many countries began stocking up on toilet paper and other household items. Large crowds of people provided the conditions for the spread of the disease. Hoarding leads to commodity shortage in supermarkets and the market was in turmoil following with stocks falling by their daily limit, which are not conducive to the stable development of society. Therefore, the mental health of the masses should a non-negligible part of the public opinion guidance in emergencies. Besides, during the outbreak of Covid-19, many families have heard or witnessed severe trauma caused by the epidemic to the family, especially the death of a loved one, with great helplessness, grief, and even despair. In the absence of self-adjustment ability and the ability of decompression part of groups, the retaliation may vent their evolution into a powerful, inner drive, rely on the activation of individual violence and the use of violence motivated. Due to the fear of unknown diseases and deaths, the shortage of medical resources and information asymmetry, some patients or family members did not cooperate with medical staff and even attacking the doctor violently. Some people conceal the truth of their physical signs, living history and contact history, which makes it difficult to prevent and control the disease. Some people even take some revenge actions, such as spitting on the elevator button. These behaviors undoubtedly 
further aggravate people's panic and even cause social unrest. As Covid-19 spreads rapidly around the world and the number of deaths increases, many countries around the world are in a panic. At this time, the relevant departments need to pay more attention to people's mental health, to avoid people's excessive anxiety, panic, and even some extreme behaviors.

Our research found that after Wuhan was quarantined, a considerable proportion of people's anxiety increased, which was reflected in Negative emotion, Behavioral response, Physiological response. The proportion of people who said their anxiety had increased in Wuhan was higher than that in other regions. This shows that people are prone to anxiety, panic and other mental health problems in areas with serious epidemics People in medical isolation have lower rates of psychological problems than those who are not. Although job and marital status were not related with the change of anxiety, people's anxiety all increased. These illustrate that with the spread of the epidemic, people are increasingly aware of the fact that public health emergency is closely related to their own health and safety. As a public health emergency, the outbreak of Covid-19 has eight characteristics, namely, sudden, clustering, unexpected, seriousness, diversity, lethality, comprehensiveness, systematicness. Therefore, it is easy to appear group panic in the crowd [22]. The increasing numbers of confirmed cases, severe cases and deaths as well as the expansion of infection regions indicate the high infectivity and heavy injury of the disease, raising the social worries and people's anxiety. Moreover, some unscientific and nasty speculation and rumors caused some people's radically panic response.

Medical isolation is unusual for ordinary people. In the face of a strange and uncertain situation, we often have dissatisfaction because of the limitation of self-control of the environment. The social isolation and loneliness followed are easy to increase the risk of mental disorders [23]. However, our study found that the anxiety of people who were in medical isolation increased less than those who were not. There are two possible reasons for this phenomenon. On the one hand, the government has taken active and effective measures for the population in medical isolation, including medical rescue and living subsidies. Confirmed or suspected coronavirus-infected patients will get subsidies to cover their medical costs from authorities and the local government will subsidize close contacts' living consumption during the period of isolation [24]. Arguably, except for the disease itself, there are almost no other worries for them. On the other hand, accompanied and cared by professionals, they may have a better understanding of their own situation, which makes them no longer feel worried, feared or anxious excessively. This illustrates that when dealing with the epidemic, it is better for authorities to solve the worries about people's medical expenses and avoid people giving up treatment or even concealing their illness because they are afraid of the high cost of treatment. However, although medical isolation had a protective effect on people's psychological state, all three aspects of people's anxiety were positively related with longer time of medical isolation, that is to say, longer time of medical isolation would increase people's anxiety. Higher degree of the attention on the epidemic would increase people anxiety as well.

Based on the importance of mental health, we proposed intervention measures for mental health from the government, individuals and the international community:

First of all, the government should pay close attention to the psychological state of the people while controlling the epidemic. On the one hand, ensure the openness, transparency and timeliness of information to avoid people's unreasonable speculation and panic. Citizens' trust in government is crucial to their perceptions of social risks so as to affect their mental health. Care and policy are likely to be delayed and inadequate in the absence of information [25] as well. National authorities should promptly respond to public opinion concerns, clarify facts, publish the truth to eliminate rumors, and create a healthy public opinion environment [26]. On the other hand, though the guideline for emergency psychological crisis intervention was released early [27], it has not been fully implemented. Many people don't know who and how to turn to for help. Relevant departments could make full use of the mass media to help people who are difficult to self-adjust [28, 29]. For example, providing psychological consultation services by setting up a crisis intervention hotline or opening a psychological adjustment public live broadcast platform. Besides, the authorities should make great efforts to combat illegal, disorderly acts and abnormal behaviors according to law to improve the 
social adaptability of the target population in the emergency and the sense of security of the entire population.

For individuals, health is the fundamental guarantee of all life activities. People should strictly adopt corresponding protective measures to avoid risk of infection such as adopting medical isolation at home, and exercise as actively as possible for it will improve health both physiology and psychology [30, 31]. In order not to be affected by panic, anxiety, depression or other negative emotions, people should reduce concerns on the epidemic itself and pay attention to their mental health and take some measures to release themselves in-time. Don't hesitate to seek help from professional people or institutions if needed. In addition, they should keep calm and rational, learn information through credible channels and discern unverified information.

\title{
5. Conclusions
}

The epidemic and regional isolation increased anxiety of people especially people in severe epidemic areas, which was reflected in negative emotion, behavior response and physiological response. Covid-19 is the public enemy of the world, which will cause indelible losses to people's health and all fields of society. Asymptomatic carriers could acquire and transmit Covid-19 indicates that the prevention and control of Covid-19 would be challenging [32]. With the spread of Covid-19, people are getting anxious, nervous and scared. Excessive stress and anxiety will lead to improper behavior, thus affecting the stability and development of the society. The epidemic and regional isolation increased anxiety of people, which was reflected in negative emotion, behavior response and physiological response. The measure of medical isolation at home should be advocated. Yet people should reduce the concern for the epidemic itself while paying attention to self-protection and the relevant departments should take active measures to control the epidemic quickly. Social and economic losses caused by the epidemic may be inevitable, but we could make great efforts to improve existing work as much as possible to minimize losses. Protecting mental health is such a vital aspect. Relative authorities and people should take proper precautions to minimize the risk when battling the epidemic.

\begin{abstract}
Abbreviations: ANOVA: one-way analysis of variance; Covid-19: Coronavirus Disease 2019; KMO: KaiserMeyer-Olkin; MLR: multiple-linear-regression; PCA: principal-component-analysis; PSM: propensity-scorematching
\end{abstract}

Author Contributions: L.Z. designed the survey, analyzed data and wrote the manuscript; Q.C. designed the survey, collected and analyzed data, and wrote the manuscript; Y.Y. revised the manuscript; H.Y. collected data; S.Z. collected; X.T. edited the manuscript. All authors have read and approved the manuscript in its final form.

Funding: This research received no external funding.

Acknowledgments: The authors thank all the respondents willing to participate in the survey. The authors also like to thank teacher Tan and Wuhan University for making this study possible.

Conflicts of Interest: The authors declare no conflict of interest.

\section{References}

1. Chinazzi M, Davis JT, Ajelli M, Gioannini C, Litvinova M, Merler S, Piontti APY, Mu K, Rossi L, Sun K et al: The effect of travel restrictions on the spread of the 2019 novel coronavirus (COVID-19) outbreak. SCIENCE 2020.

2. Nelson C, Lurie N, Wasserman J: Assessing Public Health Emergency Preparedness: Concepts, Tools, and Challenges. ANNU REV PUBL HEALTH 2007(28):1-18.

3. Ornell F, Schuch JB, Sordi AO, Paim Kessler FH: "Pandemic fear" and COVID-19: mental health burden and strategies. REV BRAS PSIQUIATR 2020, 42(3):232-235.

4. Zhang J, Wu W, Zhao X, Zhang W: Recommended psychological crisis intervention response to the 2019 novel coronavirus pneumonia outbreak in China: a model of West China Hospital. Precision Clinical Medicine 2020, Article in press. 
5. Bao Y, Sun Y, Meng S, Shi J, Lu L: 2019-nCoV epidemic: address mental health care to empower society. THE LANCET 2020, 10224(395):E37-E38.

6. Chen Q, Liang M, Li Y, Guo J, Fei D, Wang L, He L, Sheng C, Cai Y, Li X et al: Mental health care for medical staff in China during the COVID-19 outbreak. THE LANCET Psychiatry 2020.

7. Zhang W: After panic and passion: fight the new coronavirus with reason and science. JOURNAL OF MICROBES AND INFECTIONS 2020, 1(15):1.

8. Wang Y, McKee M, Torbica A, Stuckler D: Systematic Literature Review on the Spread of Health-related Misinformation on Social Media. SOC SCI MED 2019, 240(112552).

9. Goldmann E, Galea S: Mental Health Consequences of Disasters. ANNU REV PUBL HEALTH 2014(35):169-183.

10. Perna G, Caldirola D, Bellodi L: Panic disorder: from respiration to the homeostatic brain. ACTA NEUROPSYCHIATR 2004, 2(16):57-67.

11. Grant JB, Bruce CP, Batterham PJ: Predictors of personal, perceived and self-stigma towards anxiety and depression. EPIDEMIOL PSYCH SCI 2016, 3(25):247-254.

12. Reardon S: Ebola's mental-health wounds linger in Africa. NATURE 2015, 519(7541):13-14.

13. Zhang Y, Ma ZF: Impact of the COVID-19 Pandemic on Mental Health and Quality of Life among Local Residents in Liaoning Province, China: A Cross-Sectional Study. INT J ENV RES PUB HE 2020, 17(7).

14. Garcia R: Neurobiology of fear and specific phobias. LEARN MEMORY 2017, 24(9):462-471.

15. Shigemura J, Ursano RJ, Morganstein JC, Kurosawa M, Benedek DM: Public responses to the novel 2019 coronavirus (2019-nCoV) in Japan: Mental health consequences and target populations. PSYCHIAT CLIN NEUROS 2020, 74(4):281-282.

16. Kang L, Li Y, Hu S, Chen M, Yang C, Yang BX, Wang Y, Hu J, Lai J, Ma X et al: The mental health of medical workers in Wuhan, China dealing with the 2019 novel coronavirus. The Lancet Psychiatry 2020.

17. Xiang Y, Yang Y, Li W, Zhang L, Zhang Q, Cheung T, Ng CH: Timely mental health care for the 2019 novel coronavirus outbreak is urgently needed. The Lancet Psychiatry 2020.

18. Beck AT, Epstein N, Brown G, Steer RA: An inventory for measuring clinical anxiety: Psychometric properties. J CONSULT CLIN PSYCH 1988, 56(6):893-897.

19. Guo S, Fraser MW: Propensity Score Analysis: Statistical Methods and Applications. In Propensity Score Analysis: Statistical Methods and Applications. Edited by Guo Z, Wu X: Chongqing University Press; 2012.

20. Guo H: From Mind to Body:Social Stratification and Its Impact on Psychological Mechanism of Body. Chinese Journal of Sociology 2016(2):146.

21. Zhang L, Jiang J, Wang P: Social cohesion associated with health mediated by emotional experience and life satisfaction: Evidence from the internal migrants in China.

22. Liao H, Xiao J, Sun Z: "Psychological first aid" during the period of "quarantining epidemic area" -psychological and behavioral countermeasures against "group psychological panic". Chinese Journal of Hygiene Rescue (Electronic Edition) 2020, 6(1).

23. Ziggi Ivan Santini P, Paul E Jose P, Erin York Cornwell P, Ai Koyanagi MD, Line Nielsen P, Carsten Hinrichsen M, Charlotte Meilstrup P, Katrine R Madsen P, Vibeke Koushede P: Social disconnectedness, perceived isolation, and symptoms of depression and anxiety among older Americans (NSHAP): a longitudinal mediation analysis. The Lancet Public Health 2020(1):e62.

24. MOF, NHC: China boosts financial aid for epidemic treatment.; 2020.

25. Baekkeskov E, Rubin O: Information Dilemmas and Blame-Avoidance Strategies: From Secrecy to Lightning Rods in Chinese Health Crises. GOVERNANCE 2017, 30(3):425-443.

26. Ding L, Cai W, Ding J, Zhang X, Cai Y, Shi J, Liang Q, Zhang L, Sun L, Qu J et al: An interim review of lessons from the Novel Coronavirus (SARS-CoV-2) outbreak in China. SCIENTIA SINICA Vitae 2020(16747232).

27. CDC: Notice on guidelines for novel coronavirus infection emergency psychological crisis intervention.; 2020 .

28. Karmegam D, Ramamoorthy T, Mappillairajan B: A Systematic Review of Techniques Employed for Determining Mental Health Using Social Media in Psychological Surveillance During Disasters. DISASTER MED PUBLIC 2019, 1-8.

29. Hadi TA, Fleshler K: Integrating Social Media Monitoring Into Public Health Emergency Response Operations. DISASTER MED PUBLIC 2016, 5(10):775-780.

30. Faulkner GEJ, Taylor AH: Exercise, health and mental health : emerging relationships.: Routledge; 2005. 
31. McDowell CP, Gordon BR, Andrews KL, MacDonncha C, Herring MP: Associations of physical activity with anxiety symptoms and status: results from The Irish longitudinal study on ageing. EPIDEMIOL PSYCH SCI 2019, 4(28):436-445.

32. Bai Y, Yao L, Wei T, Tian F, Jin D, Chen L, Wang M: Presumed Asymptomatic Carrier Transmission of COVID-19. JAMA 2020. 